\title{
Assessment of the risk of loss of hearing generated by the hazardous exposures during the work process
}

\author{
Haralambie Vochitoiu ${ }^{1 *}$, Camelia Lavinia Unguras ${ }^{1}$, Narcis Nicolae Popa ${ }^{1}$, Dan Dumitru \\ Pintilie $^{1}$, Philippe Yves Daniel Huber ${ }^{1}$, Anton Darcy ${ }^{1}$, and Gabriel Ioan Ilcea ${ }^{1}$ \\ ${ }^{1}$ University of Petrosani - Doctoral School, 20 Universitatii street, 332006, Petrosani, Hunedoara \\ county, Romania
}

\begin{abstract}
This research presents an integrated methodological approach to probabilistic / statistical analysis and assessment of the risk of hearing loss, taking into account the dangers expressed as risk predictors, in order to establish ways to determine the prudential limits corresponding to the value areas of acceptability. Statistical evaluation is based on the rational quantification of the observable reality, the probabilistic part of this fact being the extrapolation to what can be reasonably deduced from these statistics for the assessment of the probability of hearing impairment.
\end{abstract}

\section{Introduction}

People who are regularly exposed to dangerous levels of noise can experience hearing loss of varying severity, which leads to a impaired speech comprehension and the perception of acoustic signals produced during work or daily activities. Excepting the exposure to the effects of explosion-type phenomena, high impulse noise, and extremely high levels of stationary noise, permanent damage to the auditory organ may occur over time, being progressive depending on the exposure period. [1]

The permanent movement of the threshold caused by noise is usually preceded by a temporary and reversible effect on the hearing called "temporary change in the threshold caused by noise", whose severity and mode of recovery depend on the level of exposure and time. Given that the precise determination of the unequivocal delineation of changes in audibility threshold levels caused by exposure to noise or other factors is difficult in the case of one-off addressing at the level of each individual, it was opted to calculate variations in statistical distributions of audibility threshold levels specific to a population exposed to a predefined noise. In this regard, in order to show the differences in the levels of audibility thresholds between two groups of people who are similar in all important respects, except that one of the populations has occupational noise exposure, statistical parameters of average or median related to the permanent displacement of the threshold produced by noise can be used successfully $[2,3]$.

\footnotetext{
*Corresponding author: hvochitoiu@gmail.com
} 
There are countries in which hearing impairment caused by exposure to occupational noise has legal consequences, the solution of this issue being ensured by compliance with the principles of liability and compensation. The level of the audibility threshold at different frequencies at which it is considered that a hearing impairment may occur (threshold level) depends not only on the deterioration itself, but also on the legal aspects based on social and economic considerations. At the same time, the definition of the concept of hearing impairment depends on the desired quality of speech intelligibility, the average level of background noise and, in relation to the relative importance of different frequencies, perhaps even the language spoken. Given that hearing impairment caused by dangerous exposure to noise is not only the result of occupational noise exposure but also of the total noise exposure of the population, it is necessary to take into account the non-occupational exposure of individuals (on the way to or from at their services, at home and during recreational activities, etc.). The prognosis of hearing impairment due to hazardous exposure to occupational noise is possible if non-occupational exposure is negligible compared to occupational exposure, in which case it is necessary to determine hearing impairment due to total and combined daily exposure (occupational and non-occupational) to noise, and if desired, the contribution to total hearing impairment as a result of exposure to occupational noise can also be estimated. [4].

\section{Generalized analytical tool for assessing the risk of hearing impairment due to hazardous exposure to noise}

Accidental inclusion of factors other than natural aging may affect the likelihood of the assessment of hearing quality by age categories of a population not exposed to noise. [5]. At the same time, certain diseases, discomfort caused by ototoxic drugs and random exposure to occupational noise can influence "the threshold of hearing associated with age".

To determine the age-related threshold of audibility use dedicated databases, one of which is fully specified (A), the other being at the user's discretion (B). Database A comes from otologically normal people (people who have a normal state of health) who do not show signs / symptoms of disease of the auditory organ, there are no wax plugs in the ear canals, they are not excessively exposed to noise. In the case of database B, a packet of data collected from a control population that has not been exposed to noise during the work process shall be indicated. Also, the selection of databases is made according to the nature of the problem proposed for solution.

Estimation of the permanent displacement of the threshold caused by noise

a) Determination of $N_{0.50}$

The values of the permanent displacement of the threshold produced by the noise are determined according to the audiometric frequency, the exposure time, the ratio $\theta / \theta_{0}$ and the level of exposure to standard noise at a nominal working day of 8 hours, $\mathrm{L}_{\mathrm{EX}, 8 \mathrm{~h}}$ mediated by the exposure time $\theta$. Expression (1) apply where: $\mathrm{L}_{\mathrm{EX}, 8 \mathrm{~h}}>\mathrm{L}_{0}$, otherwise the standard noise exposure level at a nominal working day of $8 \mathrm{~h}$ is: $\left(\mathrm{L}_{\mathrm{EX}, 8 \mathrm{~h}}\right)=\mathrm{L}_{0}$, so that $\mathrm{N}_{0.50}=0$. In this sense, for exposure periods with times of $10 \div 40$ years, the values of the permanent displacement of the threshold produced by noise (potential medians) are given in the case of populations of both sexes, by the following mathematical expression: 


$$
N_{0.50_{f_{i}}}=\left\{\left[\begin{array}{c}
-0.033_{f_{1}} \\
-0.02_{f_{2}} \\
-0.045_{f_{3}} \\
0.012_{f_{4}} \\
0.025_{f_{5}} \\
0.019_{f_{6}}
\end{array}\right]+\left[\begin{array}{c}
0.11_{f_{1}} \\
0.07_{f_{2}} \\
0.066_{f_{3}} \\
0.037_{f_{4}} \\
0.025_{f_{5}} \\
0.024_{f_{6}}
\end{array}\right] \lg \left(\theta / \theta_{0}\right)\right\} \cdot\left\{L_{E X, 8 h}-\left[\begin{array}{l}
93_{f_{1}} \\
89_{f_{2}} \\
80_{f_{3}} \\
77_{f_{4}} \\
75_{f_{5}} \\
77_{f_{6}}
\end{array}\right]\right\}
$$

In which:[93500Hz, $\left.89_{1000 \mathrm{~Hz}}, \quad 80_{2000 \mathrm{~Hz}}, \quad 77_{3000 \mathrm{~Hz}}, \quad 75_{4000 \mathrm{~Hz}}, \quad 77_{6000 \mathrm{~Hz}}\right]$ - value range corresponding to the sound pressure limit level determined as a function of frequency, $\mathrm{L}_{0}(\mathrm{~dB}) ; \theta$ (years) - exposure time, $\theta_{0}=1$ year; $\mathrm{L}_{\mathrm{EX}, 8 \mathrm{~h}}$ - standard noise exposure level at a nominal working day of $8 \mathrm{~h} ; \mathrm{f}_{1}=500 \mathrm{~Hz}, \mathrm{f}_{2}=1000 \mathrm{~Hz}, \mathrm{f}_{3}=2000 \mathrm{~Hz}, \mathrm{f}_{4}=3000 \mathrm{~Hz}, \mathrm{f}_{5}=4000 \mathrm{~Hz}$, $\left.\mathrm{f}_{6}=6000 \mathrm{~Hz}\right],(\mathrm{i}=1 \div 6)$ - audiometric frequency values.

For periods of less than 10 years, $\mathrm{N}$ will be extrapolated from the value of $\mathrm{N}_{0.50}$ corresponding to a period of 10 years, so:

$$
N_{0.50}^{\theta<10 \text { years }}=[\lg (\theta+1) / \lg 11] . N_{0.50}^{\theta=10 \text { years }},
$$

\section{b) Statistical distribution function of $N$}

The statistical distribution of $\mathrm{N}$ is approximated by two different halves of two normal (Gaussian) distribution functions, namely: the upper half for the quantile with hearing less than the median which is above the median value $\mathrm{N}_{0.50}$ and the lower half below the median $\mathrm{N}_{0.50}$, the following cases exist:

1. If $0.05 \leq \mathrm{Q} \leq 0.50$ then $\mathrm{N}_{\mathrm{Q}}$ it is:

$$
\left[\begin{array}{l}
N_{0.05}^{0.95} \\
N_{0.1}^{0.90} \\
N_{0.15}^{0.85} \\
N_{0.80}^{0.00} \\
N_{0.25}^{0.75} \\
N_{0.30}^{0.70} \\
N_{0.35}^{0.65} \\
N_{0.40}^{0.60} \\
N_{0.45}^{0.55} \\
N_{0.50}^{0.050}
\end{array}\right]=N_{0.5 f_{f_{i}}}+\left[\begin{array}{l}
1.645 \\
1.282 \\
1.036 \\
0.842 \\
0.675 \\
0.524 \\
0.385 \\
0.253 \\
0.126 \\
0.000
\end{array}\right]\left\{\left[\begin{array}{l}
0.044_{f_{1}} \\
0.022_{f_{2}} \\
0.031_{f_{3}} \\
0.007_{f_{4}} \\
0.005_{f_{5}} \\
0.013_{f_{6}}
\end{array}\right]+\left[\begin{array}{c}
0.016_{f_{1}} \\
0.016_{f_{2}} \\
-0.002_{f_{3}} \\
0.016_{f_{4}} \\
0.009_{f_{5}} \\
0.008_{f_{6}}
\end{array}\right] \lg \left(\theta / \theta_{0}\right)\right\} .\left\{L_{E X, 8 h}-\left[\begin{array}{l}
93_{f_{1}} \\
89_{f_{2}} \\
80_{f_{3}} \\
77_{f_{4}} \\
75_{f_{5}} \\
77_{f_{6}}
\end{array}\right]\right\}
$$

2. If $0.50 \leq \mathrm{Q} \leq 0.95$ then $\mathrm{N}_{\mathrm{Q}}$ it is:

$$
\left[\begin{array}{l}
N_{0.05}^{0.95} \\
N_{0.1}^{0.90} \\
N_{0.15}^{0.85} \\
N_{0.80}^{0.80} \\
N_{0.25}^{0.75} \\
N_{0.30}^{0.70} \\
N_{0.35}^{0.65} \\
N_{0.40}^{0.60} \\
N_{0.45}^{0.55} \\
N_{0.50}^{0.50}
\end{array}\right]=N_{0.50_{f_{i}}}-\left[\begin{array}{c}
1.645 \\
1.282 \\
1.036 \\
0.842 \\
0.675 \\
0.524 \\
0.385 \\
0.253 \\
0.126 \\
0.000
\end{array}\right]\left\{\left[\begin{array}{c}
0.033_{f_{1}} \\
0.02_{f_{2}} \\
0.016_{f_{3}} \\
0.029_{f_{4}} \\
0.016_{f_{5}} \\
0.028_{f_{6}}
\end{array}\right]+\left[\begin{array}{c}
0.002_{f_{1}} \\
0.000_{f_{2}} \\
0.000_{f_{3}} \\
-0.01_{f_{4}} \\
-0.002_{f_{5}} \\
-0.007_{f_{6}}
\end{array}\right] \lg \left(\frac{\theta}{\theta_{0}}\right)\right\} \cdot\left\{L_{E X, 8 h}-\left[\begin{array}{l}
93_{f_{1}} \\
89_{f_{2}} \\
80_{f_{3}} \\
77_{f_{4}} \\
75_{f_{5}} \\
77_{f_{6}}
\end{array}\right]\right\}
$$


In which:[1.645; $1.282 ; 1.036 ; 0.842 ; 0.675 ; 0.524 ; 0.385 ; 0.253 ; 0.126 ; 0.000]-$ the values of the multiplication factor $\mathrm{k}$ in intervals equal to the ratio of 0.05 for the quantile $\mathrm{Q}$; $\left[93_{500 \mathrm{~Hz}}, 89_{1000 \mathrm{~Hz}}, 80_{2000 \mathrm{~Hz}}, 77_{3000 \mathrm{~Hz}}, 75_{4000 \mathrm{~Hz}}, 77_{6000 \mathrm{~Hz}}\right.$ - value range corresponding to the sound pressure limit level determined depending of function of frequency, $\mathrm{L}_{0}(\mathrm{~dB}) ; \theta(\mathrm{years})$ - exposure time, $\theta_{0}=1$ year; $\mathrm{L}_{\mathrm{EX}, 8 \mathrm{~h}}$ - standard noise exposure level at a nominal working day of $\left.8 \mathrm{~h} ; \mathrm{f}_{1}=500 \mathrm{~Hz}, \mathrm{f}_{2}=1000 \mathrm{~Hz}, \mathrm{f}_{3}=2000 \mathrm{~Hz}, \mathrm{f}_{4}=3000 \mathrm{~Hz}, \mathrm{f}_{5}=4000 \mathrm{~Hz}, \mathrm{f}_{6}=6000 \mathrm{~Hz}\right],(\mathrm{i}=1 \div 6)$ audiometric frequency values.

\section{Hearing impairment calculation and auditory disability produced by noise}

The potential hearing impairment as a result of exposure to noise during work is determined directly by the permanent displacement of the threshold caused by noise, which may be: considered separately for each frequency of interest; collected for a certain number of frequencies resulting in a total threshold shift; mediated on a number of selected frequencies that define the main frequency range that characterizes speech intelligibility. The determination of hearing impairment can be performed on the basis of a combination of auditory threshold levels at specified frequencies, as follows: average auditory threshold

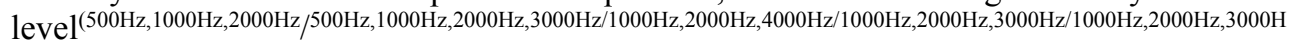
$\mathrm{z}, 4000 \mathrm{~Hz} / 2000 \mathrm{~Hz}, 4000 \mathrm{~Hz} / 2000 \mathrm{~Hz}, 3000 \mathrm{~Hz}, 4000 \mathrm{~Hz})$. The risk of hearing impairment due to exposure to noise and due to age or exposure to noise alone is the expression of the negative effects of noise exposure embodied in the potential for specific harm to a population. [6].

Determining the database A

Mathematical expressions used to calculate the level of audibility threshold $\mathrm{H}$ associated with age Y (years) for different intervals of the Q quantile that has a threshold level greater than the value $\mathrm{H}_{\mathrm{Q}}$ are the following:

For $0.05 \leq \mathrm{Q} \leq 0.50$ and $\mathrm{f}_{\mathrm{i}}=[125 \mathrm{~Hz}, 250 \mathrm{~Hz}, 500 \mathrm{~Hz}, 1000 \mathrm{~Hz}, 1500 \mathrm{~Hz}, 2000 \mathrm{~Hz}, 3000 \mathrm{~Hz}$, $4000 \mathrm{~Hz}, 6000 \mathrm{~Hz}, 8000 \mathrm{~Hz}], \mathrm{i}=1 \div 10$, then $\mathrm{H}_{\mathrm{Q}}$ it is:

$$
\left.\left(\begin{array}{l}
N_{0.05}^{0.95} \\
N_{0.1}^{0.90} \\
N_{0.15}^{0.85} \\
N_{0.20}^{0.80} \\
N_{0.25}^{0.75} \\
N_{0.30}^{0.75} \\
N_{0.35}^{0.65} \\
N_{0.40}^{0.60} \\
N_{0.45}^{0.55} \\
N_{0.50}^{0.50}
\end{array}\right)=N_{0.50_{f_{i}}}+\left(\begin{array}{c}
1.645 \\
1.282 \\
1.036 \\
0.842 \\
0.675 \\
0.524 \\
0.385 \\
0.253 \\
0.126 \\
0.000
\end{array}\right) \cdot\left[\begin{array}{c}
7.23_{f_{1}} \\
6.67_{f_{2}} \\
6.12_{f_{3}} \\
6.12_{f_{4}} \\
6.67_{f_{5}} \\
7.23_{f_{6}} \\
7.78_{f_{7}} \\
8.34_{f_{8}} \\
9.45_{f_{9}} \\
10.56_{f_{10}}
\end{array}\right)+0.445 H_{0.50}\right]
$$

For a male population 


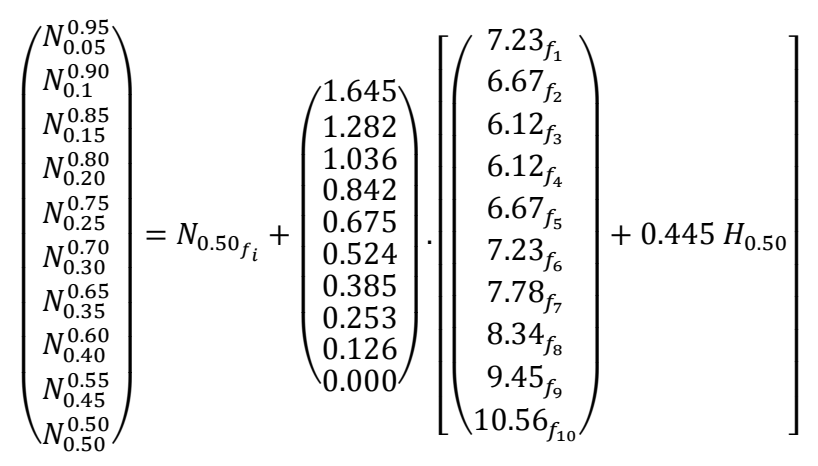

For a female population

3. If $0.50 \leq \mathrm{Q} \leq 0.95$ then $\mathrm{H}_{\mathrm{Q}}$ it is:

$$
\left.\left(\begin{array}{l}
N_{0.05}^{0.95} \\
N_{0.1}^{0.90} \\
N_{0.15}^{0.85} \\
N_{0.20}^{0.80} \\
N_{0.25}^{0.75} \\
N_{0.30}^{0.70} \\
N_{0.35}^{0.65} \\
N_{0.40}^{0.60} \\
N_{0.45}^{0.55} \\
N_{0.50}^{0.50}
\end{array}\right)=N_{0.50_{f_{i}}}+\left(\begin{array}{l}
1.645 \\
1.282 \\
1.036 \\
0.842 \\
0.675 \\
0.524 \\
0.385 \\
0.253 \\
0.126 \\
0.000
\end{array}\right) \cdot\left[\begin{array}{l}
5.78_{f_{1}} \\
5.34_{f_{2}} \\
4.89_{f_{3}} \\
4.89_{f_{4}} \\
5.34_{f_{5}} \\
5.78_{f_{6}} \\
6.23_{f_{7}} \\
6.67_{f_{8}} \\
7.56_{f_{9}} \\
8.45_{f_{10}}
\end{array}\right)+0.356 H_{0.50}\right]
$$

For a male population

$$
\left.\left(\begin{array}{c}
N_{0.05}^{0.95} \\
N_{0.1}^{0.90} \\
N_{0.15}^{0.85} \\
N_{0.20}^{0.80} \\
N_{0.25}^{0.75} \\
N_{0.30}^{0.70} \\
N_{0.35}^{0.65} \\
N_{0.40}^{0.60} \\
N_{0.45}^{0.55} \\
N_{0.50}^{0.50}
\end{array}\right)=N_{0.50_{f_{i}}}+\left(\begin{array}{c}
1.645 \\
1.282 \\
1.036 \\
0.842 \\
0.675 \\
0.524 \\
0.385 \\
0.253 \\
0.126 \\
0.000
\end{array}\right) \cdot\left[\begin{array}{c}
5.34_{f_{1}} \\
4.89_{f_{2}} \\
4.89_{f_{3}} \\
4.89_{f_{4}} \\
5.34_{f_{5}} \\
5.34_{f_{6}} \\
5.78_{f_{7}} \\
6.23_{f_{8}} \\
7.12_{f_{9}} \\
8.45_{f_{10}}
\end{array}\right)+0.356 H_{0.50}\right]
$$

For a female population

The procedural mechanism of the generalized mathematical model for estimating the risk of hearing impairment

To estimate the risk of hearing impairment the mathematical grapho-analytical model has the following phases:

(F1): Defining the problem that consists in establishing the type of population (male/female); the age of the subjects within the analyzed population; daily noise exposure level every day for $n$ years (8h/day, 5 days/week, 50 weeks/year);

(F2): Establishing the combination of frequencies for mediating audibility threshold levels;

(F3): Determining $\mathrm{H}_{\mathrm{Q}}$ for the population of a certain type (male/female) not exposed to noise according to database A; At the same time, the verification of the mathematical 
expression regarding the sum of the values between the permanent displacement of the threshold produced by the noise and the level of the audibility threshold associated with age, which if it is higher than $40 \mathrm{~dB}$, then significantly changes the result and therefore the value of the permanent displacement of the threshold produced by the noise is corrected according to the relation: $\mathrm{N}-(\mathrm{HxN}) / 120$;

(F4): Determination of the permanent displacement of the threshold caused by noise:

$$
H^{\prime}=H+N-\frac{H x N}{120}
$$

(F5): Calculating the level of the audibility threshold associated with age and noise for the population exposed to noise;

(F6): Graphic representation in Gaussian coordinates (within a rectangular system of axes in which on the abscissa are highlighted as a percentage, at the bottom the values of those with poor hearing (from right to left) / at the top the values of those with better hearing (from left to right), and on the ordinate the values of the audibility threshold level expressed in $\mathrm{dB}$ );

(F7): Determination of the risk of hearing impairment corresponding to a level of daily noise exposure each day over a period of time (expressed in years), with data specific to the levels of the hearing threshold associated with age in database A.

\section{$\checkmark$ Application for estimating the risk of hearing impairment}

The mechanism of the mathematical model involves the development of the following phases [7]:

(F1): Population: female (age 50 years); daily noise exposure level every day for 30 years (8h/day, 5 days/week, 50 weeks/year): $\mathrm{L}_{\mathrm{EX}, 8 \mathrm{~h}}=90 \mathrm{~dB}(\mathrm{~A})$;

(F2): The combination of frequencies is used to determine hearing impairment $1000 \mathrm{~Hz}$, $2000 \mathrm{~Hz}$ and $4000 \mathrm{~Hz}$;

(F3): Audibility threshold level associated with age $\mathrm{H}_{\mathrm{Q}}$ for the population not exposed to noise is calculated according to database A (table 1), being mediated for frequencies $1000 \mathrm{~Hz}$, $2000 \mathrm{~Hz}$ and $4000 \mathrm{~Hz}$, respective:

Table 1. Audibility thereshold level values associated with age (female)

\begin{tabular}{|c|c|c|c|c|c|c|c|c|c|}
\hline \multicolumn{10}{|c|}{ AUDIBILITY THRESHOLD LEVEL, dB } \\
\hline $\begin{array}{c}\text { Frequency } \\
\text { Hz }\end{array}$ & 0.9 & 0.8 & 0.7 & 0.6 & 0.5 & 0.4 & 0.3 & 0.2 & 0.1 \\
\cline { 2 - 10 } & \multicolumn{10}{|c|}{ Female } \\
\hline 500 & -4 & -2 & 0 & 2 & 4 & 6 & 8 & 10 & 13 \\
\hline 1000 & -4 & -1 & 1 & 2 & 4 & 6 & 8 & 11 & 14 \\
\hline 2000 & -4 & 0 & 3 & 5 & 7 & 10 & 13 & 16 & 21 \\
\hline 3000 & -2 & 3 & 6 & 9 & 12 & 15 & 19 & 23 & 28 \\
\hline 4000 & 0 & 6 & 10 & 13 & 16 & 20 & 25 & 30 & 36 \\
\hline 6000 & 0 & 7 & 11 & 15 & 18 & 23 & 28 & 33 & 41 \\
\hline
\end{tabular}

Selection of audibility threshold level values, in $\mathrm{dB}$, from database A 


$$
\left(\begin{array}{l}
N_{0.1 ; 50}^{0.90} \\
N_{0.2 ; 50}^{0.80} \\
N_{0.3 ; 50}^{0.70} \\
N_{0.4 ; 50}^{0.60} \\
N_{0.5 ; 50}^{0.50} \\
N_{0.6 ; 50}^{0.40} \\
N_{0.7 ; 50}^{0.30} \\
N_{0.8 ; 50}^{0.20} \\
N_{0.9 ; 50}^{0.10}
\end{array}\right)=\left(\begin{array}{c}
\frac{(-4-4+0)}{3} \\
\frac{(-1+0+6)}{3} \\
\frac{(1+3+10)}{3} \\
\frac{(2+5+13)}{3} \\
\frac{(4+7+16)}{3} \\
\frac{(6+10+20)}{3} \\
\frac{(8+13+25)}{3} \\
\frac{(11+16+30)}{3} \\
\frac{(14+21+36)}{3}
\end{array}\right)=\left(\begin{array}{c}
-2.7 \\
1.7 \\
4.7 \\
6.7 \\
9.0 \\
12.0 \\
15.3 \\
19.0 \\
23.7
\end{array}\right)
$$

The values of hearing threshold level associated with age $\mathrm{H}_{\mathrm{Q}}$ for the population not exposed to noise

(F4): At the frequency of $4000 \mathrm{~Hz}$ the sum of the values for the permanent displacement of the noise threshold and the level of the audibility threshold associated with the age for the quantile 0.1 is greater than $40 \mathrm{~dB}$ (according to table 1). Therefore, the value of $19 \mathrm{~dB}$ in table 2 is reduced as follows:

$$
19-\frac{36 \times 19}{120}=13.3 \mathrm{~dB}
$$

\begin{tabular}{|c|c|c|c|c|c|c|c|c|c|}
\hline \multicolumn{10}{|c|}{$\begin{array}{c}\text { NIPTS, dB } \\
\text { Noise exposure level LEX,8h }=90 \mathrm{~dB}\end{array}$} \\
\hline \multirow{2}{*}{$\begin{array}{c}\text { Frequency } \\
\mathbf{H z}\end{array}$} & \multicolumn{9}{|c|}{ Exposure time 30 years } \\
\hline & 0.9 & 0.8 & 0.7 & 0.6 & 0.5 & 0.4 & 0.3 & 0.2 & 0.1 \\
\hline & 0 & 0 & 0 & 0 & 0 & 0 & 0 & 0 & 0 \\
\hline 1000 & 0 & 0 & 0 & 0 & 0 & 0 & 0 & 0 & 0 \\
\hline 2000 & 3 & 4 & 4 & 5 & 5 & 6 & 7 & 8 & 9 \\
\hline 3000 & 8 & 9 & 9 & 11 & 11 & 13 & 14 & 16 & 18 \\
\hline 4000 & 10 & 11 & 12 & 13 & 14 & 15 & 16 & 17 & 19 \\
\hline 6000 & 5 & 7 & 8 & 8 & 9 & 10 & 11 & 13 & 15 \\
\hline
\end{tabular}

Table 2. The permanent displacement of the audibility threshold produced by noise

Permanent displacement of the audibility threshold produced by noise, in $\mathrm{dB}$

$$
\left(\begin{array}{l}
N_{0.1 ; 30}^{0.90} \\
N_{0.2 ; 30}^{0.80} \\
N_{0.3 ; 30}^{0.70} \\
N_{0.4 ; 30}^{0.60} \\
N_{0.5 ; 30}^{0.50} \\
N_{0.6 ; 30}^{0.40} \\
N_{0.7 ; 30}^{0.30} \\
N_{0.8 ; 30}^{0.20} \\
N_{0.9 ; 30}^{0.10}
\end{array}\right)=\left(\begin{array}{l}
\frac{(0+3+10)}{3} \\
\frac{(0+4+11)}{3} \\
\frac{(0+4+12)}{3} \\
\frac{(0+5+13)}{3} \\
\frac{(0+5+14)}{3} \\
\frac{(0+6+15)}{3} \\
\frac{(0+7+16)}{3} \\
\frac{(0+8+17)}{3} \\
\frac{(0+9+13.3)}{3}
\end{array}\right)=\left(\begin{array}{l}
4.3 \\
5.0 \\
5.3 \\
6.0 \\
6.3 \\
7.0 \\
7.7 \\
8.3 \\
7.4
\end{array}\right)
$$

The values related to the permanent displacement of the threshold produced by noise 
(F5): By applying the mathematical expression regarding the sum between the level of the audibility threshold associated with age $\mathrm{H}$ and the permanent displacement of the threshold produced by real or potential $\mathrm{N}$ noise, an approximation of biological events results:

$$
\left(\begin{array}{l}
H_{0.9}^{\prime} \\
H_{0.8}^{\prime} \\
H_{0.7}^{\prime} \\
H_{0.6}^{\prime} \\
H_{0.5}^{\prime} \\
H_{0.4}^{\prime} \\
H_{0.3}^{\prime} \\
H_{0.2}^{\prime} \\
H_{0.1}^{\prime}
\end{array}\right)=\left(\begin{array}{c}
-2.7 \\
1.7 \\
4.7 \\
6.7 \\
9.0 \\
12.0 \\
15.3 \\
19.0 \\
23.7
\end{array}\right)+\left(\begin{array}{l}
4.3 \\
5.0 \\
5.3 \\
6.0 \\
6.3 \\
7.0 \\
7.7 \\
8.3 \\
7.4
\end{array}\right)-\frac{1}{120}\left(\begin{array}{c}
-2.7 \\
1.7 \\
4.7 \\
6.7 \\
9.0 \\
12.0 \\
15.3 \\
19.0 \\
23.7
\end{array}\right) \cdot\left(\begin{array}{l}
4.3 \\
5.0 \\
5.3 \\
6.0 \\
6.3 \\
7.0 \\
7.7 \\
8.3 \\
7.4
\end{array}\right)=\left(\begin{array}{c}
1.7 \\
6.6 \\
9.8 \\
12.4 \\
14.8 \\
18.3 \\
22.0 \\
26.0 \\
30.0
\end{array}\right)
$$

(F6): The results obtained previously are represented graphically in Gaussian coordinates (figure 1).

Percentage of those with better hearing, \%

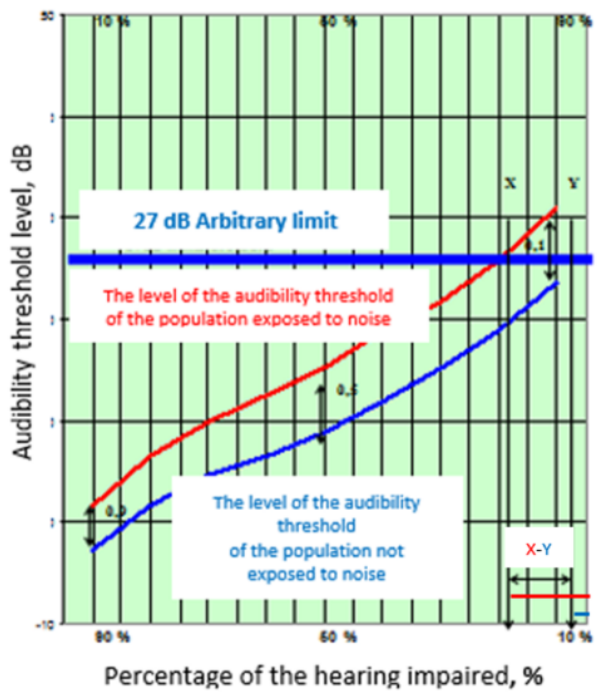

Fig.1. Graphical representation of the risk of hearing damage

(F7): Risk of hearing impairment due to age and noise: $\mathrm{X}=18 \%$; Risk of disability of the population: $Y=6.5 \%$; Risk of hearing impairment due to noise exposure: $X-Y=11.5 \%$.

\section{Conclusions}

To determine the level of the audibility threshold associated with age, established databases are used, one of which is completely specified, the other being at the user's discretion.

To estimate the risk of hearing impairment, a graphical-analytical mathematical model was developed in six procedural steps that ensures the determination of the risk of hearing impairment due to noise exposure by the difference between the risk of hearing impairment due to age and noise and the risk of hearing impairment.

The prognosis of hearing impairment due to hazardous exposure to occupational noise is possible if non-occupational exposure is negligible compared to occupational exposure, in which case it is necessary to determine hearing impairment due to total and combined daily 
exposure (occupational and non-occupational) to noise, and if desired, the contribution to total hearing impairment as a result of exposure to occupational noise can also be estimated.

\section{References}

1. J. Kotus, B. Kostek, Archives of Acoustics, J., 33, 435-440, (2008)

2. P.G. Papazoglou, Safety Science, J., 48, 943-949, (2010)

3. S. Savić, Lj. Vučković, B. Anđelković, Proceedings of III International Conference Risk in Technological Systems and the Environment, Human operator as a risk factor in technological system, (Niš, 1997).

4. E.B. Macdonald, B. Baranski, J. Wilford, Occupational Medicine in Europe: Scope and Competencies, (WHO European Centre for Environment and Health, 2008).

5. G.D.Vasilescu, Metode de calcul probabilistic utilizate in diagnoza si prognoza riscului industrial, (Editura INSEMEX, Romania, 2008)

6. ISO 1999:2013, Estimation of noise-induced hearing loss (2013)

7. W. Babisch, G. Dutilleux, M. Paviotti, A. Backman, B. Gergely, B. McManus, L.B. Coelho, J. Hinton, S. Kephalopoulos, M. Van den Berg, G. Licitra, S. Rasmussen, N. Blanes, C. Nugent, P. De Vos, A. Bloomfield, EU Good Practice Guide, Noise at work, (Luxembourg: Office for Official Publications of the European Union, 2010) 